OPEN ACCESS

Edited by:

Sergio J. Ochatt,

INRA UMR 1347 Agroécologie,

France

Reviewed by:

Pasquale Tripodi,

Council for Agricultural and Economics Research, Italy

Bernadette Julier, Institut National de la Recherche Agronomique Centre Montpellier,

France

*Correspondence:

Anete Pereira de Souza anete@unicamp.br

Specialty section:

This article was submitted to

Plant Breeding,

a section of the journal

Frontiers in Plant Science

Received: 09 October 2018 Accepted: 21 January 2019

Published: 21 February 2019

Citation:

Ferreira RCU, Lara LAdC, Chiari L, Barrios SCL, do Valle $C B$, Valério JR, Torres FZV, Garcia AAF and de Souza AP (2019) Genetic

Mapping With Allele Dosage Information in Tetraploid Urochloa decumbens (Stapf) R. D. Webster Reveals Insights Into Spittlebug

(Notozulia entreriana Berg) Resistance. Front. Plant Sci. 10:92.

doi: 10.3389/fpls.2019.00092

\section{Genetic Mapping With Allele Dosage Information in Tetraploid Urochloa decumbens (Stapf) R. D. Webster Reveals Insights Into Spittlebug (Notozulia entreriana Berg) Resistance}

Rebecca Caroline Ulbricht Ferreira', Letícia Aparecida de Castro Lara², Lucimara Chiari ${ }^{3}$, Sanzio Carvalho Lima Barrios ${ }^{3}$, Cacilda Borges do Valle ${ }^{3}$, José Raul Valério ${ }^{3}$, Fabrícia Zimermann Vilela Torres ${ }^{3}$, Antonio Augusto Franco Garcia ${ }^{2}$ and Anete Pereira de Souza ${ }^{1,4 *}$

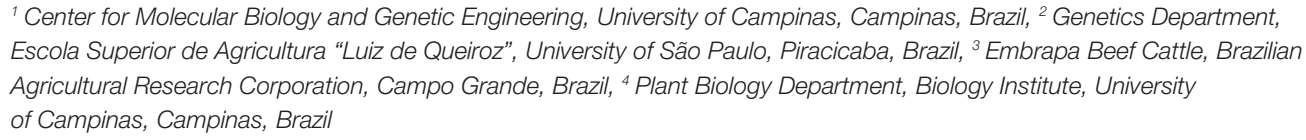
Escola Superior de Agricultura "Luiz de Queiroz", University of São Paulo, Piracicaba, Brazil, ${ }^{3}$ Embrapa Beef Cattle, Brazilian Agricultural Research Corporation, Campo Grande, Brazil, ${ }^{4}$ Plant Biology Department, Biology Institute, University of Campinas, Campinas, Brazil

Urochloa decumbens (Stapf) R. D. Webster is one of the most important African forage grasses in Brazilian beef production. Currently available genetic-genomic resources for this species are restricted mainly due to polyploidy and apomixis. Therefore, crucial genomic-molecular studies such as the construction of genetic maps and the mapping of quantitative trait loci (QTLs) are very challenging and consequently affect the advancement of molecular breeding. The objectives of this work were to (i) construct an integrated $U$. decumbens genetic map for a full-sibling progeny using GBS-based markers with allele dosage information, (ii) detect QTLs for spittlebug (Notozulia entreriana) resistance, and (iii) seek putative candidate genes involved in defense against biotic stresses. We used the Setaria viridis genome a reference to align GBS reads and selected 4,240 high-quality SNP markers with allele dosage information. Of these markers, 1,000 were distributed throughout nine homologous groups with a cumulative map length of $1,335.09 \mathrm{cM}$ and an average marker density of $1.33 \mathrm{cM}$. We detected QTLs for resistance to spittlebug, an important pasture insect pest, that explained between 4.66 and $6.24 \%$ of the phenotypic variation. These QTLs are in regions containing putative candidate genes related to defense against biotic stresses. Because this is the first genetic map with SNP autotetraploid dosage data and QTL detection in $U$. decumbens, it will be useful for future evolutionary studies, genome assembly, and other QTL analyses in Urochloa spp. Moreover, the results might facilitate the isolation of spittlebug-related candidate genes and help clarify the mechanism of spittlebug resistance. These approaches will improve selection efficiency and accuracy in U. decumbens molecular breeding and shorten the breeding cycle.

Keywords: allele dosage, Brachiaria, linkage map, polyploidy, signalgrass, SNP, quantitative traits 


\section{INTRODUCTION}

Brazilian cultivated pastures are the basis for the production of beef cattle, and they cover extensive areas, most of which are populated by grasses of the genus Urochloa (syn. Brachiaria) (Jank et al., 2011; Associação Brasileira das Indústrias Exportadoras de Carne [ABIEC], 2016). This genus belongs to the Poaceae family and comprises species of plants distributed in tropical and subtropical regions, mainly in the African continent (Renvoize et al., 1996; Valle et al., 2009).

One of the most widely cultivated species of genus is Urochloa decumbens (Stapf) R. D. Webster, also known as signalgrass. This forage grass has relevant agronomic attributes, including exceptional adaptation to poor and acidic soils that are typical of the tropics, leading to good animal performance (Valle et al., 2010). However, the species is susceptible to several types of spittlebug, including Notozulia entreriana Berg (Hemiptera: Cercopidae), which is the most damaging pest for tropical pastures (Gusmão et al., 2016).

Spittlebugs reduce biomass production, decrease palatability, and reduce the carrying capacity of pastures (Valério and Nakano, 1988). N. entreriana nymphs constantly suck the sap of roots, causing yellowing of the plant, and the saliva of the adults induces phytotoxemia that causes plant death (Valério and Nakano, 1992; Gusmão et al., 2016). Therefore, breeding programs aim to develop new cultivars with reasonable or high resistance to spittlebugs to reduce forage loss. To achieve this advance, it is essential to understand the genetic mechanisms involved in the spittlebug resistance response in forage grass and to identify valuable markers for selection in breeding schemes. Currently, spittlebug resistance in Urochloa grasses is thought to be under relatively simple genetic control and is highly heritable (Miles et al., 1995; Miles et al., 2006). Therefore, despite being a trait with little genetic information, spittlebug resistance can probably be easily manipulated in a plant breeding program.

Genetic breeding of $U$. decumbens is recent and has proven challenging because this grass is predominantly tetraploid $(2 \mathrm{n}=4 \mathrm{x}=36)$ and apomictic, reproducing mainly by facultative apospory (Naumova et al., 1999; Valle et al., 2008). In this scenario, the number of currently available molecular genetic resources is limited. Previous molecular studies have increased knowledge of $U$. decumbens genetics, including the development of sets of microsatellite markers (Ferreira et al., 2016; Souza et al., 2018) and the first transcriptome (Salgado et al., 2017) of the species as well as linkage maps from the interspecific progeny of $U$. decumbens $\times U$. ruziziensis (Worthington et al., 2016). Other studies with molecular markers have analyzed the genetic relationships of this species to other species in the Urochloa genus (Almeida et al., 2011; Pessoa-Filho et al., 2017; Triviño et al., 2017).

Until recently, it was not possible to perform intraspecific crossings due to the ploidy barriers between apomictic (polyploid) and sexual (diploid) accessions, but this restriction changed when diploid accessions were artificially tetraploidized using colchicine (Simioni and Valle, 2009). This advance allowed the generation of a base population and the exploration of a genetic variability previously conserved by apomixis, favoring new molecular studies, including building genetic linkage maps, which provide useful information about the species.

Genetic maps are essential tools for genetics and genomics research, and they are becoming increasingly common in polyploids species, mainly due to the development of nextgeneration-sequencing (NGS) technologies and advances in genetic and statistical methods (Garcia et al., 2013). In this study, we utilized the genotyping-by-sequencing (GBS) technique, which enables the discovery of 1000s of SNP at low cost (Elshire et al., 2011; Poland et al., 2012). In addition, robust software tools have been developed for polyploid organisms, including programs that can estimate the allele dosage of SNPs and provide more genetic information to generate linkage maps with high marker densities (Serang et al., 2012; Garcia et al., 2013; Mollinari and Serang, 2015; Bourke et al., 2016, 2018; Gerard et al., 2018).

The mapping process is more complex in polyploid species, mainly because of the larger number of possible genotypes (Ripol et al., 1999; Garcia et al., 2013; Vigna et al., 2016). For example, in autotetraploid species, five possible dosage classes exist: nulliplex (aaa), simplex (Aaaa), duplex (AAaa), triplex (AAAa), and quadruplex (AAAA). Most polyploid genetic maps have been limited to the use of single-dose markers (SDMs). In this case, either each marker is considered as a single-allele copy from only one of the parents of the cross, with a 1:1 segregation ratio, or the SDMs in both parents segregate in a 3:1 ratio (Wu et al., 1992). This method has been developed and successfully adopted for various forage grass species, such as Panicum maximum (Ebina et al., 2005), Paspalum notatum (Stein et al., 2007), Panicum virgatum (Okada et al., 2010), and Urochloa humidicola (Vigna et al., 2016). However, SDMs represent only a partial sample of loci available in the genome, and not all configurations that can be present in the progeny. All possible offspring genotype configurations in an autotetraploid cross were detailed by Hackett et al. (2013) and have been considered in this work. Knowledge of the dosage of an SNP is essential for genetic studies in polyploid species and can significantly increase the information imparted by each locus (Voorrips et al., 2011; Garcia et al., 2013; Bourke et al., 2016, 2018).

High-resolution genetic linkage mapping for polyploid species can identify beneficial trait loci and allow genomics-based breeding programs (Shirasawa et al., 2017). Molecular markers have been widely used to locate quantitative trait loci (QTLs) associated with quantitative resistance to insects in many crop plants (Samayoa et al., 2015; Oki et al., 2017; Vosman et al., 2018); however, genomic loci related to resistance to spittlebugs have not been determined in any plant species. Particularly in $U$. decumbens, the identification of loci involved in this trait is a promising tool for characterizing the genetic architecture and can assist in the design of strategies to be introduced into breeding programs in order to increase the efficiency of the selection processes and accelerate the release of new cultivars (Valle et al., 2009).

This study reports the development and application of GBS for mapping studies in an intraspecific progeny of $U$. decumbens. To the best of our knowledge, there have been no reports of QTL mapping in signalgrass. Our goals were to (i) build a GBSbased integrated genetic map using autotetraploid allele dosage 
information in a bi-parental progeny, (ii) identify QTLs related to spittlebug resistance on the integrated genetic map, and (iii) search for putative candidate genes that may be involved in spittlebug resistance.

\section{MATERIALS AND METHODS}

\section{Plant Material and DNA Extraction}

At the Brazilian Agricultural Research Corporation (Embrapa) Beef Cattle (EBC), Campo Grande/MS, an intraspecific cross was made between $U$. decumbens D24/27 (sexual accession tetraploidized by colchicine) and $U$. decumbens cv. Basilisk (tetraploid, apomictic cultivar used as the pollen donor); therefore, both parents were tetraploid. U. decumbens cv. Basilisk presents relevant agronomic traits and is therefore an important genotype to the breeding program. The full-sib progeny of $239 \mathrm{~F}_{1}$ individuals was analyzed, from which 217 hybrids were identified using SSRs markers obtained from Ferreira et al. (2016).

Leaf samples from each hybrid and both parents were collected, and genomic DNA was extracted using the DNeasy 96 Plant Kit (Qiagen GMbH, Germany). DNA concentrations were determined using a Qubit fluorometer (Invitrogen, Carlsbad, CA, United States).

\section{GBS Library Construction and Sequencing}

The GBS library was prepared at the University of Campinas following the protocol described by Elshire et al. (2011). Samples from both parents of the progeny were replicated five times for sequencing. Each individual within a library was part of a 96-plex reaction. Each DNA sample (300 ng in a volume of $10 \mu \mathrm{L}$ ) was digested with the restriction enzyme NsiI (NEB) to reduce genomic complexity and then ligated to a unique barcoded adapter plus a common adapter. The 96-plex libraries were checked for quality using an Agilent DNA 1000 Kit on an Agilent 2100 Bioanalyzer (Agilent Technologies, Santa Clara, CA, United States). Libraries sequencing was performed as 150bp single-end reads on the Illumina NextSeq 500 platform. The quality of the resulting sequence data was then evaluated with the NGS QC Toolkit v2.3.3 (Patel and Jain, 2012).

\section{SNP Calling}

SNP discovery and genotype calling were performed using TasselGBS pipeline (Glaubitz et al., 2014), which was modified to obtain the original count of the number of reads for each SNP allele (Pereira et al., 2018). Because this pipeline requires a reference genome, and because the $U$. decumbens genome has not yet been sequenced, we aligned the GBS reads using the Setaria viridis genome ( $\mathrm{v} 1.0 ; \sim 394.9 \mathrm{Mb}$ arranged in nine chromosomes and 724 scaffolds; diploid forage) as an alternative pseudogenome. This genome is available from the Phytozome website ${ }^{1}$ (Goodstein et al., 2012), and it sequence data were produced by the US Department of Energy Joint Genome Institute. The Bowtie2 algorithm version 2.1 (Langmead and Salzberg, 2012)

${ }^{1}$ http://www.phytozome.net/ was used to align reads against the pseudo-reference with -D and - $\mathrm{R}$ parameters defined as 20 and 4, respectively, and with the very-sensitive-local argument.

\section{Allele Dosage Estimation and Data Filtering}

SuperMASSA software (Serang et al., 2012; Pereira et al., 2018) was used to estimate the allele dosage (number of copies of each allele) of each individual. The minimum overall depth considered was 25 reads, and the model used was the $\mathrm{F}_{1}$ Population Model. Markers were fitted and filtered to fixed ploidy level of 4 .

Additionally, monomorphic SNP markers in the parents and in the progeny were removed, and markers with a maximum of $25 \%$ missing data were selected manually using scripts written using R software (R Core Team, 2018).

\section{Linkage Map}

A consensus linkage map was built using the TetraploidSNPMap (TPM, BioSS) software (Hackett et al., 2017), following the methodology described in Hackett et al. (2013, 2014). We used the supposed synteny between $U$. decumbens and $S$. viridis to infer the homologous groups, which were constructed separately using the SNPs identified on each relative $S$. viridis chromosome. Markers with significance of the $\chi^{2}$ goodness-of-fit statistic less than 0.001 for simplex and 0.01 for higher segregations were considered distorted and were removed by the TPM software. A total of 2,725 distorted SNPs were excluded from the cluster analyses. The remaining 1,515 non-distorted SNPs were clustered into nine homologous groups using a Chi-square test for independent segregation (Hackett et al., 2013).

Considering the ordination of markers, a two-point analysis was used to calculate the recombination frequency and LOD score for each pair of SNPs in each possible phase by an expectation-maximization (EM) algorithm to maximize the likelihood. Duplicate and near-duplicate SNPs were removed in this step. The recombination frequencies were converted to map distances using Haldane's mapping function, and a multi-dimensional scaling analysis (MDS) was then performed to calculate the best order for the SNPs in the homology group. After this step, we excluded some SNPs that showed low LOD scores or that were distant from the rest of the group (Hackett et al., 2017). Some phases of the ordered SNPs were inferred by automated analysis in TetraploidSNPMap, and others were manually inferred based on the most likely phases, following the reasoning implemented in software such as OneMap (Margarido et al., 2007).

The genetic map was drawn using MapChart 2.32 (Voorrips, 2002), in which SNP configurations were identified with different colors.

\section{Phenotypic Evaluation}

The antibiosis resistance levels of $U$. decumbens to spittlebugs (N. entreriana) was evaluated in greenhouse experiments at Embrapa Beef Cattle, Brazil, according to the methodology described by Lapointe et al. (1992) and Valério et al. (1997). After establishment of seedlings, each individual was infested with five 
$N$. entreriana spittlebug eggs. The variable evaluated was the percentage of nymphal survival (number of nymphs that reached the adult stage, as a percentage), which is a quantitative trait.

From 2011 to 2013, a total of 12 experiments were conducted; each experiment had a randomized complete block design (RCBD) with different numbers of blocks and treatments. Common treatments were repeated in all experiments and were used as checks in the statistical analysis. A total of 349 individuals were evaluated for spittlebug resistance, of which 157 were hybrids of the mapping population.

In 2011, five RCBD experiments were conducted, with 10 blocks each and a total of 114 individuals evaluated. The best hybrids were selected with respect to spittlebug resistance and included in the experiments conducted in 2013, when seven RCBD experiments were conducted, with four blocks each and a total of 259 individuals evaluated. The common checks for all experiments were $U$. decumbens cv. Basilisk, U. brizantha cv. Marandu, Urochloa spp. cv. BRS Ipyporã, and Urochloa spp. MulatoII. The following statistical linear mixed model was used for the analysis:

$$
y_{i j l k}=\mu+b_{j(l)}+p_{l}+a_{k}+t_{i k}+\varepsilon_{i j l k}
$$

where $y_{i j l k}$ is the phenotype of the $i$-th individual, at $j$-th block, $l$-th experiment, and $k$-th year; $\mu$ is the overall mean; $b_{j(l)}$ is the random effect of the $j$-th block within the $l$-th experiment $\left(b_{j(l)} \sim N\left(0, \sigma_{B}^{2}\right)\right) ; p_{l}$ is the random effect of the $l$-th experiment $\left(p_{l} \sim N\left(0, \sigma p^{2}\right)\right) ; a_{k}$ is the fixed effect of the $k$-th year; $t_{i k}$ is the random effect of the $i$-th individual in the $k$-th year $\left(t_{i k} \sim\right.$ $N(0, G)$ ), in which $G$ is the variance-covariance (VCOV) matrix for genetic effects; and $\varepsilon_{i j l k}$ is the residual error $\left(\varepsilon_{i j l k} \sim N\left(0, \hat{\sigma}_{R}^{2}\right)\right)$. The $G$ matrix is indexed by two factors (genotype and year) written as the Kronecker product of matrices, $G=I_{n} \otimes G_{a}$, in which $I_{n}$ is an identity matrix relative to genotype effects and $G_{a}$ is the VCOV matrix relative to year effects. The $G_{a}$ matrix was evaluated considering six different VCOV structures: independent (ID), diagonal (DIAG), compound symmetry (CS), compound symmetry heterogeneous (CS-Het), first-order factor analytic (FA1), and unstructured (US). The selection model was performed considering the Akaike Information Criteria (AIC) (Akaike, 1974) and Schwarz Information Criteria (SIC) (Schwarz, 1978).

Phenotypic analysis was performed using the packages ASReml-R v3 (Butler et al., 2009; Gilmour et al., 2009) and ASRemlPlus (Brien, 2016). Heritability between genotype means was estimated using the index as presented by Cullis et al. (2006) and Piepho and Möhring (2007), where:

$$
\hat{\mathrm{H}}_{\mathrm{C}}^{2}=1-\frac{P E V}{2 \sigma_{G}^{2}}
$$

in which $P E V$ is the prediction error variance, and $\sigma_{G}^{2}$ is the genetic variance.

\section{QTL Mapping}

Quantitative trait loci mapping for spittlebug resistance was performed by applying an Interval Mapping (IM) model based on autotetraploid allele dosage information with TetraploidSNPMap software (Hackett et al., 2017). This analysis was performed separately for each homology group using the SNP data for each one of them, the integrated genetic map with phase information and the phenotypic trait data. The interval mapping was fit to a model of additive effects using a weighted regression approach. A significant QTL was declared if the LOD score was above the $95 \%$ threshold obtained from a permutation test with 1,000 permutations. From a significant QTL, simple models such as a simplex, duplex or double-simplex QTL models were then tested using the SIC (Schwarz, 1978) to determine if the estimated genotype corresponded to the most likely QTL location. The SIC is calculated in TetraploidSNPMap as follows:

$$
\mathrm{SIC}=-2 \log L+p \log m_{o},
$$

where $L$ is the likelihood for the simple model, $p$ is the number of parameters in the simple model, and $m_{o}$ is the number of observations (the 36 genotype means). Models with the lowest value for the SIC were considered the best models (Hackett et al., 2014).

If two closely linked significant QTLs were identified on the same chromosome, TetraploidSNPMap could not estimate the individual QTL LOD and parameter values, yielding data only pertaining to the largest effect.

\section{Search for Candidate Genes in Detected QTL Regions}

We investigated the functional annotation of the candidate genes located close to the QTL regions associated with spittlebug resistance. Using the chromosomal locations of the markers adjacent to QTLs in the $S$. viridis genome as a reference, we aligned the sequences found in these regions $(100 \mathrm{~kb}$ approximately) with a BLASTX search (e-value cutoff of 1e-0.5) against plants databases using the JBrowse too ${ }^{2}$. Finally, from this alignment, we selected only genes reported in the literature as associated with resistance/defense against biotic stresses that were present in the transcriptome of $U$. decumbens (Salgado et al., 2017), our species of study.

\section{RESULTS}

\section{SNP Calling}

The GBS library generated a total of $1,183,089,925$ raw reads ( $94 \%$ Q20 bases), with an average of 4,151,193 reads per individual. Using the Tassel-GBS pipeline modified to polyploid, alignment with the S. viridis genome enabled the identification of 58,370 SNP markers. The output of the Tassel-GBS pipeline was used as the input for the SuperMASSA software, and 9,345 SNP markers with allele dosage were selected with a minimum overall depth of 25 reads. Afterward, markers with up to $25 \%$ missing data and non-segregating markers were removed, resulting in 4,240 SNP markers that were used in the subsequent steps.

Using three different SNP markers, Figure 1 exemplifies how the SuperMASSA software uses the ratio of allele count

\footnotetext{
${ }^{2}$ http://www.phytozome.org/
} 
A)

S.5_20487325
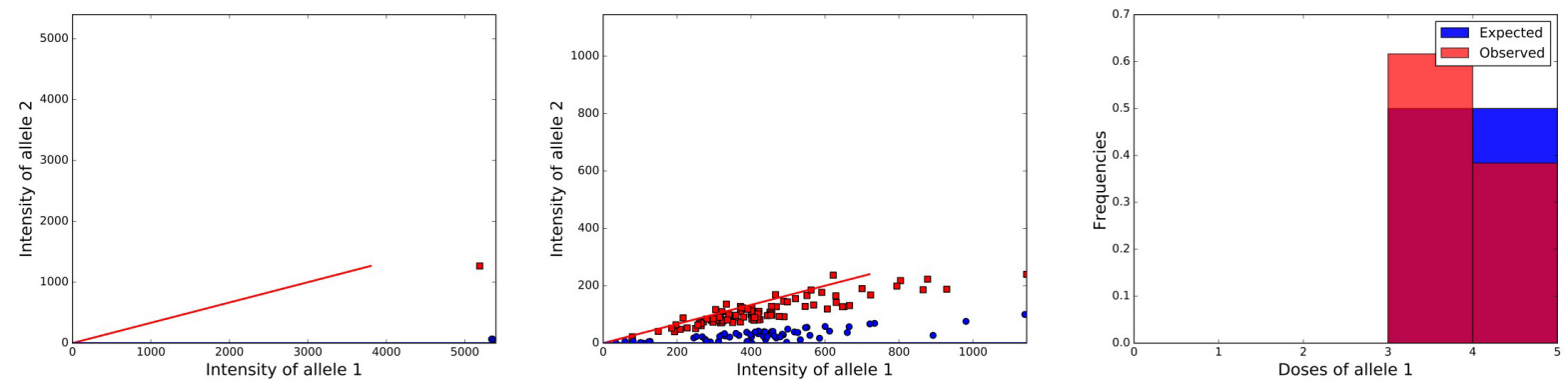

B)

D.2_28922605
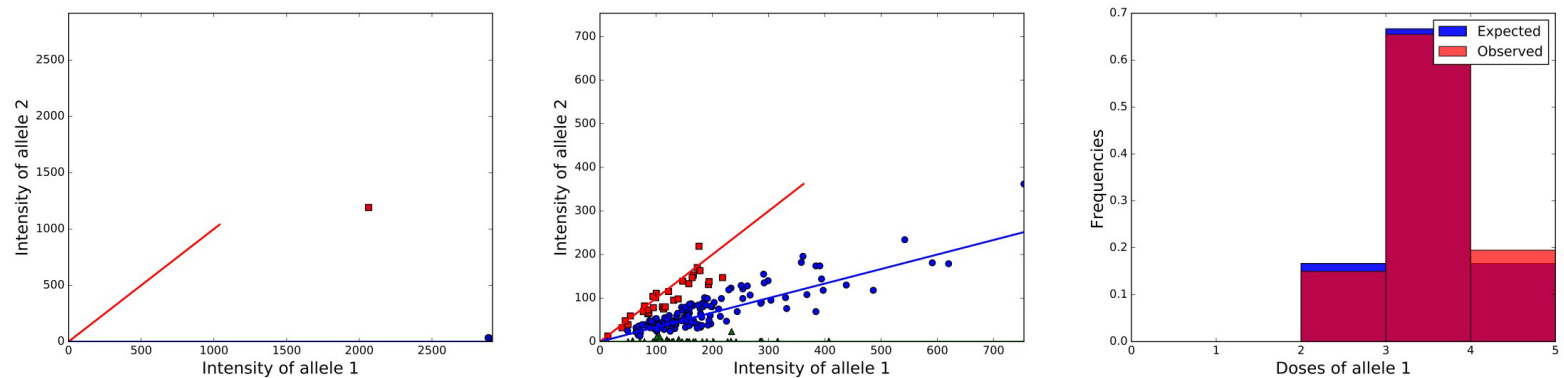

C)

XSS.1_23891474
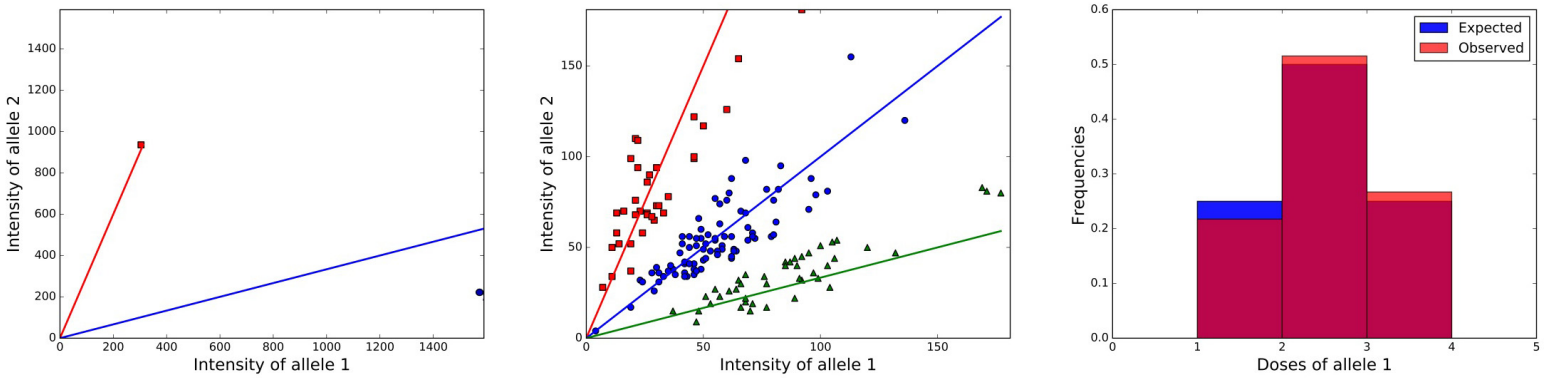

FIGURE 1 | Allele dosage in the parents and progeny, and the frequency histograms. (A) Marker S.5_20487325. Red squares represent the Aaaa parent and offspring, and blue circles represent the aaaa parent and offspring. (B) Marker D.2_28922605. Red squares represent the AAaa parent and offspring, blue circles represent the aaaa parent and the Aaaa offspring, and green triangles represent the aaaa offspring. (C) Marker XSS.1_23891474. Red squares represent AAAa parent and offspring, blue circles represent the Aaaa parent and the AAaa offspring, and green triangles represent the Aaaa offspring.

to classify individuals according to their genotypes using a probabilistic graphical model (Serang et al., 2012). The markers were named with the allele dosage configuration, the homology group number, and the chromosomal position of the SNP in the $S$. viridis genome.

GBS sequence data have been submitted to the NCBI Sequence Read Archive (SRA) under accession number SRP148665.

\section{Genetic Map}

An integrated genetic map was built using 217 full sibs obtained from a cross between $U$. decumbens cv. Basilisk (apomictic cultivar) and U. decumbens D24/27 (sexual accession) (Figures 2, 3). Of the 4,240 markers used for linkage analysis,
1,515 showed significance of the $\chi^{2}$ goodness-of-fit statistic, and 1,000 were placed in the linkage map (Table 1).

The markers were distributed throughout nine homology groups (HGs), with each $\mathrm{HG}$ therefore reflecting four chromosomes in two parents. The consensus map had a cumulative length of $1,335.09 \mathrm{cM}$ and an average marker density of $1.33 \mathrm{cM}$. The length of each group ranged from $129.70 \mathrm{cM}$ (HG5) to $166.57 \mathrm{cM}$ (HG9), with an average of $148 \mathrm{cM}$ (Table 1 and Supplementary Table S1). Homology group 9 showed the highest average density and the highest number of mapped markers (Table 1 and Figure 3).

Supplementary Figures S1, S2 and S3 show the parental genetic maps represented by the homology groups. The homology groups on the D24/27 genetic map (female parental) 
TABLE 1 | The number of GBS-based markers after significance testing, the number of mapped markers within each homology group ( $\mathrm{HG})$, and the length, marker density and largest distance between adjacent markers in each HG (cM) in the genetic map.

\begin{tabular}{lcrccc}
\hline HG & $\begin{array}{c}\text { No. GBS- } \\
\text { based } \\
\text { markers* }\end{array}$ & $\begin{array}{c}\text { No. } \\
\text { mapped } \\
\text { markers }\end{array}$ & $\begin{array}{c}\text { Length of } \\
\text { HG (cM) }\end{array}$ & $\begin{array}{c}\text { Marker } \\
\text { density } \\
\text { (cM) }\end{array}$ & $\begin{array}{c}\text { Largest distance } \\
\text { between adjacent } \\
\text { markers (cM) }\end{array}$ \\
\hline 1 & 132 & 100 & 136.74 & 1.37 & 9.1 \\
2 & 181 & 121 & 164.95 & 1.36 & 10.5 \\
3 & 219 & 138 & 151.56 & 1.10 & 10.7 \\
4 & 169 & 101 & 139.70 & 1.38 & 10.7 \\
5 & 183 & 123 & 129.70 & 1.05 & 8.4 \\
6 & 100 & 63 & 161.72 & 2.57 & 10.4 \\
7 & 154 & 99 & 140.08 & 1.41 & 9.1 \\
8 & 82 & 68 & 144.07 & 2.12 & 12.4 \\
9 & 295 & 187 & 166.57 & 0.89 & 5.2 \\
Total & 1,515 & 1,000 & $1,335.09$ & - & - \\
\hline
\end{tabular}

* Markers were selected if the $\chi^{2}$ goodness-of-fit statistic was higher than 0.001 for simplex and 0.01 for higher segregations.

ranged from $116.8 \mathrm{cM}$ (HG8) to $151.8 \mathrm{cM}$ (HG9) in size, with a cumulative map length of $1,208.33 \mathrm{cM}$ and an average marker density of $3.20 \mathrm{cM}$. The homology groups on the D62 genetic map (male parental) ranged from $129.7 \mathrm{cM}$ (HG5) to $166.57 \mathrm{cM}$ (HG9) in size, with a cumulative map length of $1,335.14 \mathrm{cM}$ and an average marker density of $1.56 \mathrm{cM}$.

The distances between adjacent markers on the consensus genetic map were plotted as a histogram, which revealed that the majority of markers were within $1 \mathrm{cM}$ of each other (Figure 4). The two largest distances between adjacent markers were located in HG8 and had lengths of $11.2 \mathrm{cM}$ and $12.4 \mathrm{cM}$ (Figure 3 and Table 1). The largest distance found on the map of the female parental was $25.01 \mathrm{cM}$ (HG6) (Supplementary Figure S2), whereas on the map of the male parental this was $22.04 \mathrm{cM}$ (HG8) (Supplementary Figure S3).

In Figures 2, 3, the possible genotype configuration of each marker is indicated by the marker name prefix and the different colors. For example, markers with the prefix $\mathrm{S}$ and the color black represent the simplex configuration (Table 2). Four homologous groups showed almost all configurations (HG1, HG3, HG5 and HG9), and simplex markers (S) were the most frequent. The $\mathrm{X}$-double-simplex (XSS) configuration was less frequent and appeared in only HG3 and HG5 (Figures 2, 3 and Table 2).

\section{Phenotypic Analysis and QTL Mapping}

The selected VCOV matrix for $G_{a}$ based on AIC was CSHet and/or US, both structures account for genetic correlation and heterogeneous variance across years. Considering the SIC, the selected VCOV matrix for $G_{a}$ was CS, in which the genetic correlation and homogeneous variance across years are considered, in addition to requiring estimation of a lower number of parameters than the previous VCOV matrices. As the difference in SIC values between CS and CS-Het/US (18880.37$18877.39=2.98)$ was greater than the respective AIC difference $(18848.03-18845.13=2.9)$, the CS matrix was used for $G_{a}$
(Table 3). The assumption of normality of the residuals can be visualized in Supplementary Figure S4.

Predicted genotypic values for spittlebug ( $N$. entreriana) resistance in progeny and checks, genetic and residual variance components and heritability are shown in Table 4 . The predicted mean among the checks ranged from 17.72 (Urochloa spp. cV. BRS Ipyporã- highly resistant) to 83.18 (U. decumbens cv. Basilisk- highly susceptible) (Table 4). As the variance components for genetic and residual effects were 68.8426 and 382.3238, respectively, the broad sense heritability results in 0.1526 (using $\sigma_{G}^{2} /\left(\sigma_{G}^{2}+\sigma_{R}^{2}\right)$ ). However, the generalized heritability is more appropriate for unbalanced designs (Cullis et al., 2006), and had value of 0.3730 (Table 4). For balanced designs, the usual broad sense heritability and the generalized heritability coincide (Piepho and Möhring, 2007), which was not our case.

Best linear unbiased prediction values were used to perform QTL mapping for spittlebug resistance by applying an IM model to the integrated genetic map. Using this method, three significant QTLs were identified for spittlebug resistance (Table 5) that were located in three homologous groups: HG1, HG2, and HG6. The obtained threshold values for LOD scores using 1,000 permutations ranged from 4.39 to 5.49 and were used to declare the presence of these QTLs. The percentages of phenotypic variation $\left(R^{2}\right)$ explained by the QTLs ranged from 4.66 to $6.24 \%$. The male progenitor of the mapping population, $U$. decumbens D62 (cv. Basilisk), contributed with the resistance alleles for these three QTLs.

In homology group 1, the QTL had a LOD score of 4.68 and explained $4.80 \%$ of the phenotypic variation for spittlebug resistance. This LOD score was above the upper 95\% LOD permutations threshold of 3.11 (Supplementary Figure S5A). This first QTL was located at position $95 \mathrm{cM}$ (Figure 2). Analyses of different simple genetic models were performed with TetraploidSNPMap to determine the best simple fitting model for the studied trait. For this QTL, the best model was a duplex genotype $(\mathrm{AAAA} \times \mathrm{BBAA})$, with the allele $\mathrm{B}$ present on parent 2 associated with spittlebug resistance. This model had the lowest SIC $($ SIC $=85.34)$ compared with the full model $(\mathrm{SIC}=102.99)$ (Table 5).

In homology group 2, the maximum LOD score was 4.39, and this QTL explained $4.66 \%$ of the phenotypic variation for spittlebug resistance. The LOD peak was located at position 60 cM (Figure 2), and its score was above the upper 95\% LOD permutation threshold of 3.29 (Supplementary Figure S5B). Again, the analysis with the simpler models estimated a duplex genotype (AAAA $\times$ BBAA) for this QTL, with the resistance allele present in parent 2. This model had the lowest SIC (SIC = 93.03) in comparison with the full model $(\mathrm{SIC}=89.55)$ (Table 5).

The QTL detected in homology group 6, had the highest LOD score, 5.49, explained $6.24 \%$ of the phenotypic variation and was above the $95 \%$ LOD permutation upper threshold of 2.79 (Supplementary Figure S5C). The QTL peak was located at $23 \mathrm{cM}$ (Figure 3), and an analysis of different genetic models indicated that an allele explains the phenotypic variation. This QTL is linked to a simplex SNP (AAAA $\times$ ABAA), with the B 


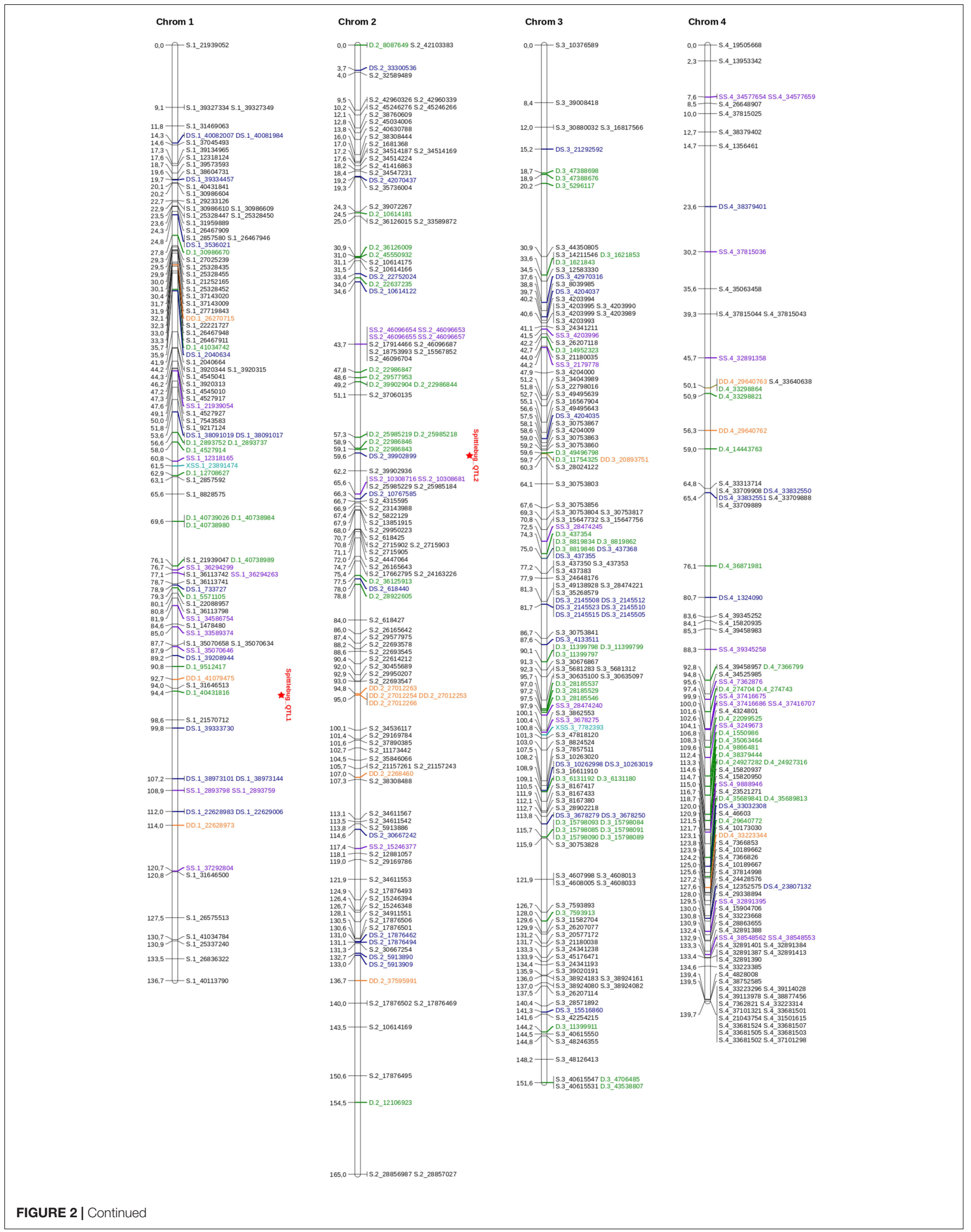


FIGURE 2 | Linkage map for U. decumbens: homologous groups from 1 to 4 . The genotype configuration of each marker is indicated by the marker name prefix and color. Simplex markers are represented in black; duplex markers are represented in green; double-simplex markers are represented in purple; X-double-simplex markers are represented in light blue; duplex-simplex markers are represented in dark blue and double-duplex markers are represented in orange. QTLs are identified in HG1 and HG2.

allele present on parent 2 associated with spittlebug resistance. This model had the lowest SIC of 99.07 compared to the full model with SIC of 115.47 (Table 5).

\section{Search for Candidate Resistance Genes}

Using the $S$. viridis genome as a reference, sequence similarity was detected in the regions of the markers adjacent to the mapped QTLs, with homologies for Arabidopsis thaliana and Oryza sativa. Functional annotation of these sequences showed possible candidate genes involved in the spittlebug resistance response (Supplementary Table S2) that are also present in the $U$. decumbens transcriptome (Salgado et al., 2017).

The first identified QTL, located in HG1, had two adjacent markers, D.1_40431816 and S.1_21570712, identified from the $S$. viridis genome reference. The region of this QTL showed similarity to pathogenesis-related gene 1 (PR1), leucinerich repeat (LRR) family protein and the WRKY11 gene, which can be involved in the response to insect attacks (Supplementary Table S2).

In HG2, the region of the GBS-based adjacent markers (DS.2_39902899 and S.2_399022936) to QTL2 showed similarity to NBS-LRR and NB-ARC protein domains and with the pentatricopeptide repeat (PPR) superfamily proteins (Supplementary Table S2).

The region of the GBS-based markers (D.6_25761630 and S.6_35357677) adjacent to QTL3 in the HG6 showed similarity to a WRKY DNA-binding protein, a kinase superfamily protein, an F-box family protein, NB-ARC protein domains and kinase superfamily proteins. This QTL region also showed similarity to the thaumatin-like protein superfamily (TLP), which is classified within the pathogenesis-related (PR) protein family, to LRR protein domains and to F-box family proteins (Supplementary Table S2).

\section{DISCUSSION}

The development of GBS technology enables the identification of thousands of SNP markers across the genome of a given species at a relatively low cost. This advance represents an evolution in genetic studies of polyploid species, since a larger part of the genome can be represented, favoring approaches such as the construction of genetic maps. The map reported here was developed using an intraspecific progeny of $U$. decumbens of Embrapa Beef Cattle and includes GBS-based markers with autotetraploid allele dosages, an approach never previously employed in a forage grass species. Although not completely elucidated, some evidence suggests that $U$. decumbens is a segmental allopolyploid (Mendes-Bonato et al., 2001; Worthington et al., 2016), considered to have arisen from hybridization between very closely related species (Stebbins, 1947).

Our molecular markers fit a tetrasomic segregation model (Supplementary Figure S6), probably because autotetraploids, as well as segmental allotetraploids, do not behave as diploids with respect to the mode of inheritance (Bourke et al., 2018). Another explanation is the fact that one of the parents of the mapping population was tetraploidized artificially and therefore behaves as autotetraploid. Therefore, we chose to use all possible SNP configurations to add even more genetic information to the genetic map. Our map provides important genomic information, such as the detection of QTLs involved in spittlebug (N. entreriana Berg) resistance, a relevant trait for breeding programs in the Urochloa genus.

We used the genome of $S$. viridis, a member of the Poaceae, or grass, family, to align our reads and discover GBS-based markers. S. viridis is a species widely used as a model in genetic studies of grasses of the subfamily Panicoideae (Li and Brutnell, 2011), such as U. decumbens. S. viridis is a phylogenetically related species to $U$. decumbens that currently has a sequenced genome with a better assembly for use in genetic studies such as ours. This alignment was sufficient to identify a relevant number $(4,240)$ of high-quality SNPs with allele dosage estimated. In previous analyses, we tested other reference genomes for our read alignment, but the $S$. viridis genome alignment produced the best results in terms of the number of markers identified (Supplementary Table S3), probably due to genetic proximity with $U$. decumbens.

Worthington et al. (2016) detected 3,912 SNP markers after filtering using the UNEAK (Universal Network-Enabled Analysis Kit) pipeline (Lu et al., 2013), which is similar to the number of markers that we detected using the $S$. viridis genome as reference. In a previous analysis, we tested the UNEAK pipeline for SNP identification in our intraspecific progeny, but this method detected fewer markers $(1,210)$ compared with alignment to the genome reference $(4,240)$. Most likely, the cross between two different species $(U$. decumbens $\times U$. ruziziensis) favored the discovery of more SNPs through the UNEAK pipeline by Worthington et al. (2016), in addition to the different methodology used for GBS library construction.

The sequences obtained herein by the GBS libraries are dynamic, allowing the raw data to be reanalyzed as bioinformatics methods evolve (Poland and Rife, 2012), as well as when some tetraploid Urochloa spp. genome is sequenced and assembled. We reinforce that our map can help in this process. Therefore, our sequences may be reanalyzed in the future to obtain a higher alignment rate, as well as to identify a larger number of markers.

Previous polyploid genetic studies have been developed with markers scored as presence/absence of alleles, but this method does not make use of all the information available in the SNP at multiple doses. The GBS data obtained here were sufficient 

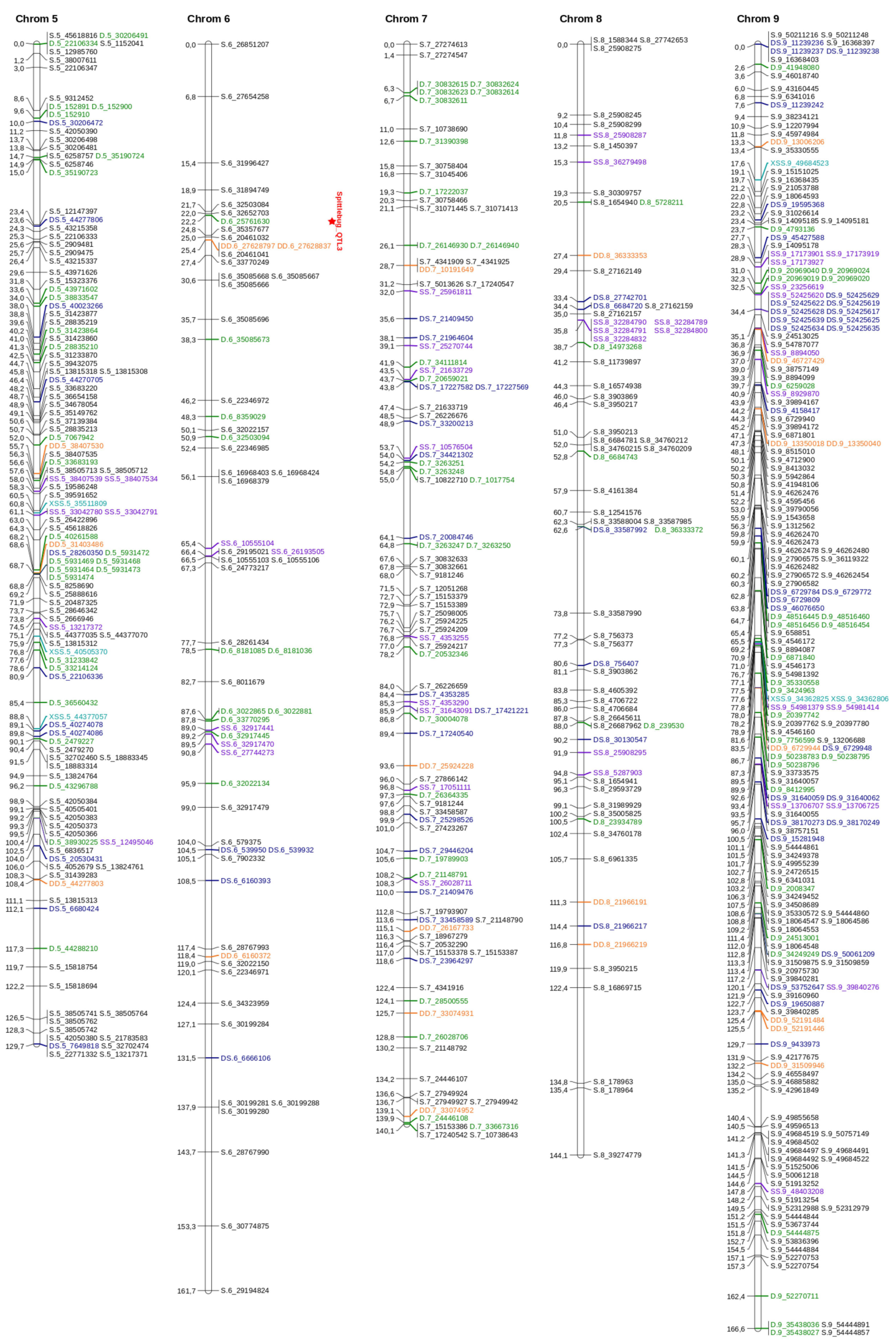

FIGURE 3 | Linkage map for U. decumbens: homologous groups from 5 to 9 . The genotype configuration of each marker is indicated by the marker name prefix and color. Simplex markers are represented in black; duplex markers are represented in green; double-simplex markers are represented in purple; X-double-simplex markers are represented in light blue; duplex-simplex markers are represented in dark blue and double-duplex markers are represented in orange. A QTL is identified in HG6. 
TABLE 2 | Distribution of SNPs into genotypic classes.

\begin{tabular}{|c|c|c|c|c|c|c|}
\hline Type & Parent 1 & Parent 2 & P1 dosage & P2 dosage & SNP initial number & Mapped SNP \\
\hline Null (N) & AAAA & BBBB & 4 & 0 & 8 & 0 \\
\hline Simplex (S) & AAAA & $\mathrm{AAAB}$ & 4 & 3 & 1, 332 & 591 \\
\hline Simplex (S) & ABBB & BBBB & 1 & 0 & & \\
\hline Triplex (T) & AAAA & ABBB & 4 & 1 & 126 & 0 \\
\hline Triplex (T) & AAAB & BBBB & 3 & 0 & & \\
\hline Duplex (D) & AAAA & AABB & 4 & 2 & 720 & 172 \\
\hline Duplex (D) & AABB & BBBB & 2 & 0 & & \\
\hline Double-simplex (SS) & AAAB & AAAB & 3 & 3 & 1,013 & 78 \\
\hline Double-simplex (SS) & ABBB & ABBB & 1 & 1 & & \\
\hline X-double-simplex (XSS) & AAAB & ABBB & 3 & 1 & 65 & 8 \\
\hline Simplex-duplex (SD) & AAAB & AABB & 3 & 2 & 11 & 0 \\
\hline Duplex-simplex (DS) & AABB & ABBB & 2 & 1 & 773 & 116 \\
\hline Double-duplex (DD) & AABB & $\mathrm{AABB}$ & 2 & 2 & 192 & 35 \\
\hline Total & & & & & 4,240 & 1,000 \\
\hline
\end{tabular}

TABLE 3 | Values of AIC and SIC for $G_{a}$ matrix, considering different VCOV structures.

\begin{tabular}{lccccc}
\hline Ga Matrix & Df & AIC & SIC & logREML & \\
\hline ID & 4 & 18868.02 & 18891.51 & -9430.010 & \\
DIAG & 5 & 18866.02 & 18895.41 & -9428.021 & \\
CS & 5 & 18848.03 & $\mathbf{1 8 8 7 7 . 3 9}$ & -9419.014 & Selected \\
CS-Het & 6 & $\mathbf{1 8 8 4 5 . 1 3}$ & 18880.37 & -9416.565 & \\
FA1 & 7 & 18847.13 & 18888.24 & -9416.565 & \\
US & 6 & $\mathbf{1 8 8 4 5 . 1 3}$ & 18880.37 & -9416.565 &
\end{tabular}

The lowest values are indicated in bold.

TABLE 4 | Summary of the predicted genotypic values for progeny and checks, genetic $\left(\hat{\sigma}_{G}^{2}\right)$ and residual $\left(\hat{\sigma}_{R}^{2}\right)$ variance and heritability $\left(\hat{H}_{C}^{2}\right)$ for spittlebug resistance.

\begin{tabular}{|c|c|c|c|c|c|}
\hline \multicolumn{3}{|c|}{ Progeny predicted means } & \multirow[t]{2}{*}{$\left(\hat{\sigma}_{G}^{2}\right)$} & \multirow[t]{2}{*}{$\left(\hat{\sigma}_{R}^{2}\right)$} & \multirow[t]{2}{*}{$\left(\hat{H}_{C}^{2}\right)$} \\
\hline Minimum & Mean & Maximum & & & \\
\hline 56.16 & 70.81 & 85.07 & 68.86 & 382.32 & 0.3730 \\
\hline Checks & & \multicolumn{2}{|c|}{ Predicted means } & \multicolumn{2}{|c|}{ Classification } \\
\hline Basilisk & & \multicolumn{2}{|l|}{83.18} & \multicolumn{2}{|c|}{ Highly susceptible } \\
\hline Marandu & & \multicolumn{2}{|l|}{38.79} & \multicolumn{2}{|c|}{ Resistant } \\
\hline Ipyporã & & \multicolumn{2}{|l|}{17.72} & \multicolumn{2}{|c|}{ Highly resistant } \\
\hline Mulatoll & & \multicolumn{2}{|l|}{55.96} & \multicolumn{2}{|c|}{ Intermediary } \\
\hline
\end{tabular}

in terms of read depth to call allele dosage in 9,345 markers from the $S$. viridis genome using SuperMASSA software (Serang et al., 2012; Pereira et al., 2018) (Supplementary Table S3). This methodology provided the distribution of alleles in the progeny and the relative intensities of each allele, increasing the amount of genetic information obtained (Serang et al., 2012; Garcia et al., 2013; Bargary et al., 2014; Pereira et al., 2018).

After analysis using SuperMASSA software (Serang et al., 2012) and subsequent filtering steps, 4,240 SNPs were obtained representing all possible configurations for an autotetraploid species. Approximately 55\% (2,345) of the
TABLE 5 | Quantitative trait loci information for the spittlebug resistance trait analyzed in the $U$. decumbens progeny.

\begin{tabular}{lcccccc}
\hline Trait & HG & $\begin{array}{c}\text { QTL } \\
\text { position } \\
\text { (cM) }\end{array}$ & LOD & $\begin{array}{c}\text { Variance } \\
\text { explained } \\
\text { (\%) }\end{array}$ & SIC & Configuration \\
\hline Nymphal survive & 1 & 95 & 4.68 & 4.80 & 85.33 & Duplex (D) \\
Nymphal survive & 2 & 60 & 4.39 & 4.66 & 93.03 & Duplex (D) \\
Nymphal survive & 6 & 23 & 5.49 & 6.24 & 99.07 & Simplex (S) \\
\hline
\end{tabular}

HG, homology group; QTL, quantitative trait locus; LODs, logarithm of the odds; SIC, Schwarz Information Criterion.

SNP markers identified from the $S$. viridis genome alignment followed the parental genotype configurations of simplex $(\mathrm{AAAA} \times \mathrm{AAAB} / \mathrm{ABBB} \times \mathrm{BBBB})$ and double-simplex $(\mathrm{AAAB} \times \mathrm{AAAB} / \mathrm{ABBB} \times \mathrm{ABBB})$. Slightly less than $1 \%$ of the identified markers followed the nulliplex $(\mathrm{AAAA} \times \mathrm{BBBB})$ and simplex-duplex $(\mathrm{AAAB} \times \mathrm{AABB})$ configurations (Table 2). These results were satisfactory and relevant for genetic studies with a tetraploid species, but a GBS library construction methodology with more than one restriction enzyme might provide a larger read depth and, accordingly, increase the number of markers detected.

The 4,240 high-quality SNP markers were inserted in TetraploidSNPMap software (Hackett et al., 2017), and 2,725 were identified with distortion from the expected Mendelian segregation ratio. Although numerous studies have shown that markers with segregation distortion can increase the density of the map and help improve QTL detection (Hu et al., 2018), the mapping software used does not allow the inclusion of such markers. Segregation distortion is a common phenomenon that can occur due to non-biological factors such as sampling and genotyping error, or due to biological factors such as gametophyte and/or zygotic selection, hybrid incompatibility, deleterious alleles or chromosomal rearrangements (ManriqueCarpintero et al., 2016; Edae et al., 2017). In our study, crossing of a natural segmental allotetraploid male parent with an artificially autotetraploidized female parent may have caused uneven 
transmission of the alternative alleles due to reduction of pairing affinity and meiotic abnormalities, causing the appearance of a large number of distorted markers. However, more detailed studies are needed to clarify this hypothesis.

The remaining 1,515 SNPs showed significance in the $\chi^{2}$ goodness-of-fit statistic, and 1,000 were placed in the linkage map (Table 1). These 1,000 SNP markers were distributed across nine homology groups, with a total length of 1,335.09 cM and an average map density of $1.33 \mathrm{cM}$ (Figures 2, 3 and Table 1), reflecting the molecular source and mapping methodology.

In Worthington et al. (2016) study, genetic maps for an interspecific progeny resulting from a cross between $U$. decumbens $\times U$. ruziziensis were built with GBS-based markers, and 1,916 SDA (single-dose allele) markers were distributed across the parental linkage maps. The different mapping method used in our study may have influenced the number of markers linked in the map. However, although our map has a lower marker density, it contains SNP markers with different allele dosages, adding more genetic information to the map and enabling more robust genetic analyses (Garcia et al., 2013). In addition, our genetic map has a higher density of markers than other Urochloa genetic maps (Thaikua et al., 2016; Vigna et al., 2016).

In our study, the density of markers per HG on the consensus map ranged from 63 (HG6) to 187 (HG9) (Figures 2, 3 and Table 1). In relation to the map of the parents, the density of polymorphic markers per HG ranged from 20 (HG6) to 78 (HG9) on the female parental map (D24/27) and from 47 (HG8) to 163 (HG9) on the male parental map (D62) (Supplementary Figures S1, S2 and S3). The greater density of markers for certain HGs may correspond to a greater recombination frequency. However, less saturated groups may have fewer SNP in these regions and/or correspond to highly homozygous regions that have lower recombination frequencies (Bai et al., 2016). We also observed a significant difference in the total number of polymorphic markers on the map of each parental: 377 markers for the female parental genetic map and 856 markers for the male parental genetic map. The lower polymorphic marker density in the map of the female parental (D24/27) is not surprising given the artificial tetraploidization process that this genotype was submitted, which could have a directly influence in the genetic variability on this parent.

The largest distance between adjacent markers on the consensus map, $12.4 \mathrm{cM}$, was observed in homology group eight (Figure 3 and Table 1), one of the groups with the fewest mapped markers. Compared with other linkage map studies, our map has low average marker intervals in all HGs (Figures 2, 3). Nevertheless, substantial intervals are common and even expected using the GBS technique, mainly due to centromeric regions, which are not reached with this methodology (Conson et al., 2018). Additionally, it is possible that the number of hybrids in the mapping population was not sufficient to observe recombination in these intervals ( $\mathrm{Ma}$ et al., 2014), that these intervals represent regions that were not captured with the methodology used or that the intervals represent distorted portions of the genome. One possible method to fill these distances is to use different combinations of enzymes to enlarge the sequencing pools and thereby enable the capture of markers in other genomic regions. Furthermore, we mapped only markers identified by aligning with the $S$. viridis genome. Therefore, these observed intervals may contain markers that are exclusive to the $U$. decumbens genome and thus cannot be represented with the methodology used. Therefore, advances in the assembly of complex polyploid genomes are expected to enable the use of the full signalgrass genome as a reference for future studies (Margarido and Heckerman, 2015).

Of the 1000 mapped SNPs, 59\% (591) followed the simplex parental genotype configuration (Figures 2, 3 and Table 2). This configuration was also the most frequent in other genetic mapping studies (Hackett et al., 2013; da Silva et al., 2017), probably because it is easily scored and analyzed. The least common configuration was X-double-simplex (XSS), followed by double-duplex (DD) (Table 2), which is the most complete configuration because it allows the representation of all types of segregation for autotetraploid species. Overall, the map displays most of the possible SNP configurations, and these data significantly increase the information about each locus and provide several advantages for genetic analysis (Garcia et al., 2013). When building genetic maps for polyploid species, the use of markers with allele dosage information allows the development of robust genetic maps that allow the detection of QTLs (Hackett et al., 2013; da Silva et al., 2017).

Until recently, no intraspecific progeny have been available for $U$. decumbens; therefore, no QTL mapping studies of this species have been performed to date. The identification of genes/loci underlying spittlebug ( $N$. entreriana) resistance is critical for forage grass molecular breeding programs because these pests severely damage pastures (Valle et al., 2009). In our study, QTL mapping for spittlebug resistance was performed by applying interval mapping for the tetraploid progeny (Hackett et al., 2017). Although more accurate QTL models are available (such as composite and multiple interval mapping), these models have not been extended to polyploidy and therefore do not use molecular markers with allele dosage information.

For the multi-allelic QTL analysis, we performed a permutation test to obtain the threshold for declaring significant QTLs. This analysis allowed the identification of three significant QTLs which explained between 4.66 and $6.24 \%$ of the phenotypic variation (Table 5). The identification of a small number of QTLs with small effects reflects the median heritability found for spittlebug resistance $\left(H_{C}{ }^{2}=0.37\right)$. Spittlebug resistance in forage grasses is probably not genetically complex but likely involves more than a single major resistance gene (Miles et al., 1995). Therefore, values of phenotypic variation and the number of QTLs detected in our analysis may be mainly due the low genetic variability for spittlebug resistance in the analyzed progeny, as the parents do not differ greatly for this trait and are both considered susceptible. Moreover, the methodology used for QTL detection and/or map saturation may have influenced these results.

Although $U$. decumbens is considered a susceptible species to the pasture spittlebug, our results showed that the segregation of different alleles in each tetraploid parent contributed to the observed polymorphisms in the progeny. Therefore, our results 


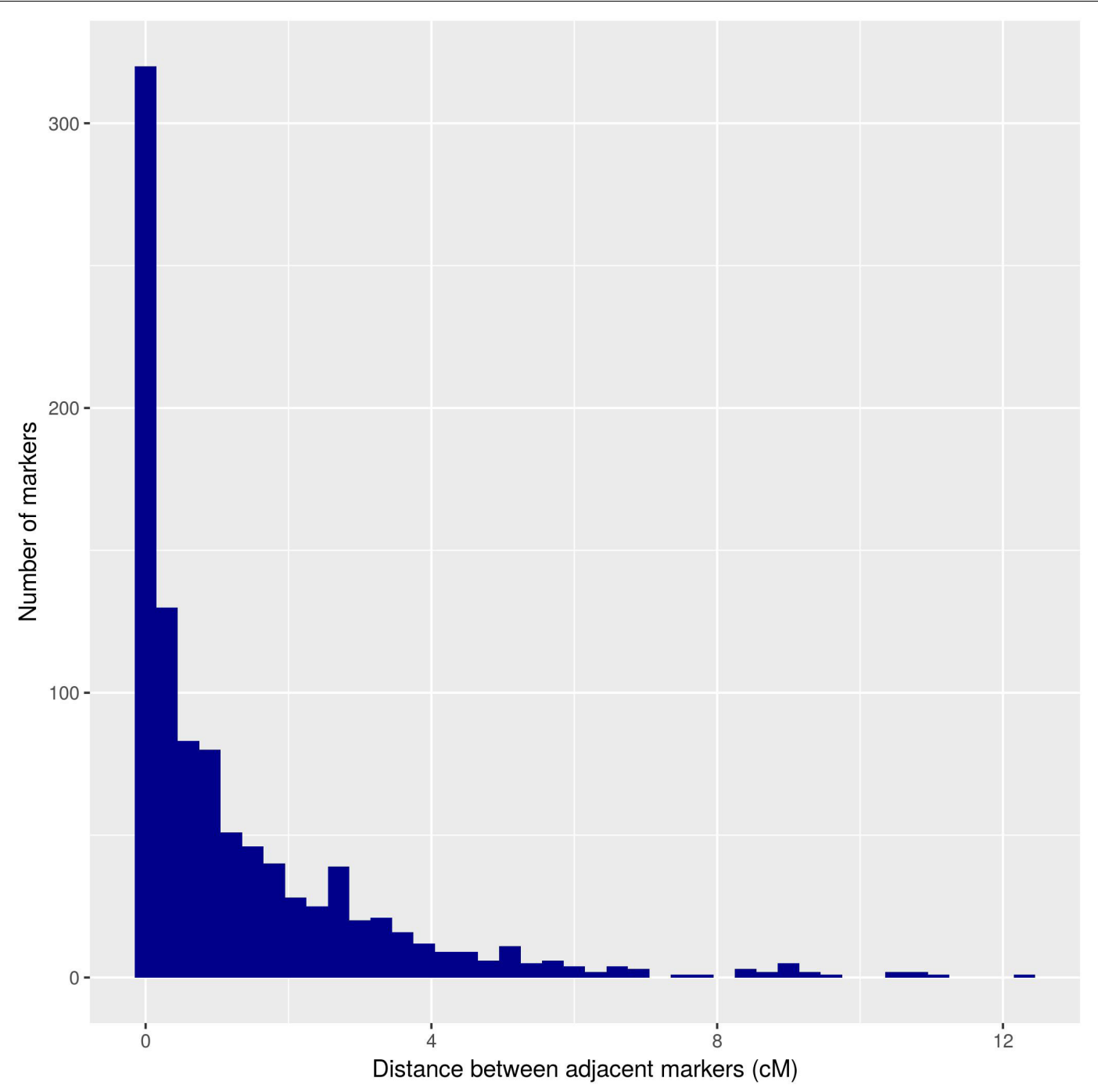

FIGURE 4 | Distribution of the distance between adjacent markers on the $U$. decumbens consensus genetic map.

can be useful for breeders to identify the alleles from the male parent that contribute to increased values of this phenotypic trait, consequently allowing genotypes that are more resistant to the development and survival of spittlebugs to be found more rapidly.

Quantitative trait loci with greater effects on spittlebug resistance are more efficient for use in breeding programs, but our results represent a great advance since it is the only study about genetic architecture using an $U$. decumbens intraspecific progeny. Therefore, the detection of these QTLs is the first step in the advancement of genomic studies involving spittlebug resistance. The annotation of sequences that originated markers with mapped QTLs is important to identify candidate genes involved in spittlebug resistance in $U$. decumbens. Thus, the regions that gave rise to these QTLs should be more thoroughly evaluated to identify more genetic information for future applications in the marker-assisted selection in signalgrass breeding programs.
To respond to mechanical damage caused by insect attacks, plants possess multiple molecular defense mechanisms (War et al., 2012). Based on an investigative and comparative analysis, the QTL regions of this study showed similarity to genes containing protein domains reported to be involved in defense responses against biotic stresses in plants (Supplementary Table S2).

For spittlebug resistance trait, we can highlight the similarity of the region of the QTL1 with pathogenesis-related gene 1 $(P R 1)$. PR proteins are induced by the plants as a defense response system in stress conditions such as insect attacks, as the PR1 gene is involved in biological processes related to defense responses and systemic acquired resistance (Metzler et al., 1991; Van Loon and Van Strien, 1999; Van loon et al., 2006; Sinha et al., 2014). This region also showed similarity to the WRKY11 gene, which plays a crucial role in cellular defense responses and defense-related gene transcriptional regulation (Jiang et al., 2016) (Supplementary Table S2). 
For QTL3, we can highlight the similarity of the region to the adjacent markers with WRKY DNA binding domains. These transcription factors are involved in plant defense responses to biotic stresses (Du and Chen, 2000; Souza et al., 2017). Moreover, F-box and WRKY DNA binding domains have orthologs in A. thaliana, with genes that develop a function in plant defense. This QTL region also showed similarity to Thaumatin-like proteins (TLPs), which play a variety of roles, including plant protection against biotic stress (Liu et al., 2010; Mukherjee et al., 2010; Misra et al., 2016).

The regions of the markers adjacent to the mapped QTLs 2 and 3 showed similarity to NBS-LRR protein domains, which are widely distributed in plants and thought to respond to pathogen attacks, including viruses, bacteria, fungi, and even insects (Song et al., 2017; Souza et al., 2017). NBS-LRRs are the most prevalent class of resistance proteins (Gupta et al., 2012). These regions also showed similarity with F-box proteins that control many important biological functions such as pathogen resistance (Lechner et al., 2006), and the PPR superfamily proteins that have been implicated in plant biotic stress responses (Xing et al., 2018). Moreover, the NB-ARC protein domain is a functional ATPase domain containing a nucleotide-binding site that is proposed to regulate plant disease resistance (Van ooijen et al., 2008).

Although we used the $S$. viridis genome as a reference to investigate the marker regions adjacent to the identified QTLs, we selected only genes that were also found in the U. decumbens transcriptome (Salgado et al., 2017) to lend greater reliability to our results. Therefore, our results provide a starting point, indicating possible candidate genes involved in spittlebug resistance in signalgrass. However further studies should be conducted to validate these genomic regions as well as the role of the candidate genes in signalgrass and their effects on phenotypic expression.

We can conclude that this recent opportunity to analyze a $U$. decumbens full-sib progeny has opened new genetic molecular perspectives for this and related species. The genetic map presented herein includes important approaches such as the estimation of tetraploid dosage of each molecular SNP and greatly increases genetic information and represents an important evolution for polyploid studies. In addition, the map allowed the identification of genomic regions related to spittlebug ( $N$. entreriana) resistance, the main insect that attacks forage grasses, providing new insights about this trait. Furthermore, the molecular data developed here are dynamic and can be applied in future studies, such as genome assembly and other QTL analyses in $U$. decumbens.

\section{AUTHOR CONTRIBUTIONS}

LC, SB, CdV, JV, FT, and AdS conceived and designed the experiments. RF, LC, SB, CdV, JV, and FT conducted the experiments and collected data. RF, LL, and AG analyzed the data and interpreted the results. RF, LL, and AdS wrote the manuscript. All authors read and approved the manuscript.

\section{FUNDING}

This work was supported by grants from the Fundação de Amparo à Pesquisa de do Estado de São Paulo (FAPESP 05/51010-0; 08/52197-4), the Conselho Nacional de Desenvolvimento Científico e Tecnológico (CNPQ), and the Coordenação de Aperfeiçoamento de Pessoal de Nível Superior (CAPES - Computational Biology Programme). RF received Ph.D. fellowships from the CAPES-Embrapa Programme and the CAPES Computational Biology Programme and PD fellowship from FAPESP (2018/19219-6), and LL received a PD fellowship from the CAPES Computational Biology Programme. AG and AdS were recipients of a research fellowship from Conselho Nacional de Desenvolvimento Científico e Tecnológico (CNPq).

\section{ACKNOWLEDGMENTS}

We would like to acknowledge the Brazilian Agricultural Research Corporation (Embrapa Beef Cattle) for providing the Urochloa decumbens progeny used in this study. We thank Aline da Costa Lima Moraes for the assistance in the GBS library construction and performing DNA sequencing. This manuscript was previously posted to bioRxiv https://www. biorxiv.org/content/early/2018/10/09/360594.

\section{SUPPLEMENTARY MATERIAL}

The Supplementary Material for this article can be found online at: https://www.frontiersin.org/articles/10.3389/fpls.2019.00092/ full\#supplementary-material

FIGURE S1 | Homology groups 1, 2, and 3 of the D24/27 maternal linkage map and of the D62 paternal linkage map. The genotype configuration of each marker is indicated by the marker name prefix and color. Simplex markers are represented in black; duplex markers are represented in green; double-simplex markers are represented in purple; $\mathrm{X}$-double-simplex markers are represented in light blue; duplex-simplex markers are represented in dark blue and double-duplex markers are represented in orange.

FIGURE S2 | Homology groups 4, 5, and 6 of the D24/27 maternal linkage map and of the D62 paternal linkage map. The genotype configuration of each marker is indicated by the marker name prefix and color. Simplex markers are represented in black; duplex markers are represented in green; double-simplex markers are represented in purple; $\mathrm{X}$-double-simplex markers are represented in light blue; duplex-simplex markers are represented in dark blue and double-duplex markers are represented in orange.

FIGURE S3 | Homology groups 7, 8, and 9 of the D24/27 maternal linkage map and of the D62 paternal linkage map. The genotype configuration of each marker is indicated by the marker name prefix and color. Simplex markers are represented in black; duplex markers are represented in green; double-simplex markers are represented in purple; X-double-simplex markers are represented in light blue; duplex-simplex markers are represented in dark blue and double-duplex markers are represented in orange.

FIGURE S4 | Residual plots.

FIGURE S5 | Interval mapping (IM) for spittlebug resistance from the $U$. decumbens mapping population in chromosomes 1 (A), 2 (B), and 6 (C). Dotted lines indicate the LOD thresholds of $90 \%$ and $95 \%$ obtained after the permutation tests. 
FIGURE S6 | Theoretical distribution of genotypes in the mapping population and the distribution of individuals assigned to each genotype. The genotype distributions are nearly identical to the theoretical distribution in an F1 population.

TABLE S1 | Homology groups with names, positions and type of markers, and information about phases for each parental.

\section{REFERENCES}

Akaike, H. (1974). A new look at the statistical model identification. IEEE Trans. Automat. Contr. 19, 716-723. doi: 10.1109/TAC.1974.1100705

Almeida, M. C. D. C., Chiari, L., Jank, L., and Valle, C. B. D. (2011). Diversidade genética molecular entre cultivares e híbridos de Brachiaria spp. e Panicum maximum. Ciênc. Rural 41, 1998-2003. doi: 10.1590/S010384782011001100024

Associação Brasileira das Indústrias Exportadoras de Carne [ABIEC] (2016). Perfil da Pecuária do Brasil: Relatório Anual. Available at: http://abiec.siteoficial.ws/ images/upload/sumario-pt-010217.pdf

Bai, Z.-Y., Han, X.-K., Liu, X.-J., Li, Q.-Q., and Li, J.-L. (2016). Construction of a high-density genetic map and QTL mapping for pearl quality-related traits in Hyriopsis cumingii. Sci. Rep. 6:32608. doi: 10.1038/srep32608

Bargary, N., Hinde, J., and Garcia, A. A. F. (2014). "Finite mixture model clustering of SNP data," in Statistical Modelling in Biostatistics and Bioinformatics, eds G. MacKenzie and D. Peng (Berlin: Springer International Publishing), 139-157. doi: 10.1007/978-3-319-04579-5_11

Bourke, P. M., Voorrips, R. E., Kranenburg, T., Jansen, J., Visser, R. G. F., and Maliepaard, C. (2016). Integrating haplotype-specific linkage maps in tetraploid species using SNP markers. Theor. Appl. Genet. 129, 2211-2226. doi: 10.1007/ s00122-016-2768-1

Bourke, P. M., Voorrips, R. E., Visser, R. G. F., and Maliepaard, C. (2018). Tools for genetic studies in experimental populations of polyploids. Front. Plant Sci. 9:513. doi: 10.3389/fpls.2018.00513

Brien, C. (2016). ASRemlPlus: Augments the Use of 'ASReml' in Fitting Mixed Models. R Package Version 2.0-9.

Butler, D. G., Cullis, B. R., Gilmour, A. R., and Gogel, B. J. (2009). ASReml-R Reference Manual, Release 3. Technical Report. Brisbane: QLD: Queensland Department of Primary Industries.

Conson, A. R. O., Taniguti, C. H., Amadeu, R. R., Andreotti, I. A. A., de Souza, L. M., Dos Santos, L. H. B., et al. (2018). High-resolution genetic map and QTL analysis of growth-related traits of Hevea brasiliensis cultivated under suboptimal temperature and humidity conditions. Front. Plant Sci. 9:1255. doi: 10.3389/fpls.2018.00513

Cullis, B. R., Smith, A. B., and Coombes, N. E. (2006). On the design of early generation variety trials with correlated data. J. Agric. Biol. Environ. Stat. 11, 381-393. doi: 10.1198/108571106X154443

da Silva, W. L., Ingram, J., Hackett, C. A., Coombs, J. J., Douches, D., Bryan, G. J., et al. (2017). Mapping loci that control tuber and foliar symptoms caused by PVY in Autotetraploid potato (Solanum tuberosum L.). G3 7, 3587-3595. doi: 10.1534/g3.117.300264

Du, L., and Chen, Z. (2000). Identification of genes encoding receptor-like protein kinases as possible targets of pathogen- and salicylic acid-induced WRKY DNAbinding proteins in Arabidopsis. Plant J. 24, 837-847. doi: 10.1046/j.1365-313x. 2000.00923.x

Ebina, M., Nakagawa, H., Yamamoto, T., Araya, H., Tsuruta, S.-I., Takahara, M., et al. (2005). Co-segregation of AFLP and RAPD markers to apospory in Guineagrass (Panicum maximum Jacq.). Grassl. Sci. 51, 71-78. doi: 10.1111/j. 1744-697X.2005.00011.x

Edae, E. A., Olivera, P. D., Jin, Y., and Rouse, M. N. (2017). Genotypingby-sequencing facilitates a high-density consensus linkage map for Aegilops umbellulata, a wild relative of cultivated wheat. G3 7, 1551-1561. doi: 10.1534/ g3.117.039966

Elshire, R. J., Glaubitz, J. C., Sun, Q., Poland, J. A., Kawamoto, K., Buckler, E. S., et al. (2011). A robust, simple genotyping-by-sequencing (GBS) approach for high diversity species. PLoS One 6:e19379. doi: 10.1371/journal.pone.001 9379
TABLE S2 | Functional description of the sequences found in the regions of the markers adjacent to mapped Urochloa decumbens QTLs for spittlebug resistance based on similarity to the Setaria viridis genome.

TABLE S3 | Number of markers identified in the alignment with five reference genomes using the Tassel-GBS pipeline after allele dosage estimation with SuperMASSA software and $R$ data filtration analysis.

Ferreira, R. C. U., Cançado, L. J., Do Valle, C. B., Chiari, L., and De Souza, A. P. (2016). Microsatellite loci for Urochloa decumbens (Stapf) R.D. Webster and cross-amplification in other Urochloa species. BMC Res. Notes 9:152. doi: 10.1186/s13104-016-1967-9

Garcia, A. A. F., Mollinari, M., Marconi, T. G., Serang, O. R., Silva, R. R., Vieira, M. L. C., et al. (2013). SNP genotyping allows an in-depth characterisation of the genome of sugarcane and other complex autopolyploids. Sci. Rep. 3:3399. doi: 10.1038/srep03399

Gerard, D., Ferrão, L. F. V., Garcia, A. A. F., and Stephens, M. (2018). Genotyping polyploids from messy sequencing data. Genetics 210, 789-807. doi: 10.1534/ genetics.118.301468

Gilmour, A. R., Gogel, B. J., Cullis, B. R., and Thompson, R. (2009). ASReml User Guide Release 3.0. Hempstead, NY: VSN Int. Ltd.

Glaubitz, J. C., Casstevens, T. M., Lu, F., Harriman, J., Elshire, R. J., Sun, Q., et al. (2014). TASSEL-GBS: a high capacity genotyping by sequencing analysis pipeline. PLoS One 9:e90346. doi: 10.1371/journal.pone.0090346

Goodstein, D. M., Shu, S., Howson, R., Neupane, R., Hayes, R. D., Fazo, J., et al. (2012). Phytozome: a comparative platform for green plant genomics. Nucl. Acids Res. 40, D1178-D1186. doi: 10.1093/nar/gkr944

Gupta, S. K., Rai, A. K., Kanwar, S. S., and Sharma, T. R. (2012). Comparative analysis of zinc finger proteins involved in plant disease resistance. PLoS One 7:e42578. doi: 10.1371/journal.pone.0042578

Gusmão, M. R., Valério, J. R., Matta, F. P., Souza, F. H. D., Vigna, B. B. Z., Fávero, A. P., et al. (2016). Warm-season (C4) turfgrass genotypes resistant to spittlebugs (Hemiptera: Cercopidae). J. Econ. Entomol. 109, 1914-1921. doi: 10.1093/jee/tow135

Hackett, C. A., Boskamp, B., Vogogias, A., Preedy, K. F., and Milne, I. (2017). TetraploidSNPMap: software for linkage analysis and QTL mapping in autotetraploid populations using SNP dosage data. J. Hered. 108, 438-442. doi: 10.1093/jhered/esx022

Hackett, C. A., Bradshaw, J. E., and Bryan, G. J. (2014). QTL mapping in autotetraploids using SNP dosage information. Theor. Appl. Genet. 127, 18851904. doi: 10.1007/s00122-014-2347-2

Hackett, C. A., McLean, K., and Bryan, G. J. (2013). Linkage analysis and QTL mapping using SNP dosage data in a tetraploid potato mapping population. PLoS One 8:e63939. doi: 10.1371/journal.pone.0063939

Hu, X. H., Zhang, S. Z., Miao, H. R., Cui, F. G., Shen, Y., Yang, W. Q., et al. (2018). High-density genetic map construction and identification of QTLs controlling oleic and linoleic acid in peanut using SLAF-seq and SSRs. Sci. Rep. 8:5479. doi: 10.1038/s41598-018-23873-7

Jank, L., Valle, C. B., and Resende, R. M. S. (2011). Breeding tropical forages. Crop Breed. Appl. Biotechnol. 11, 27-34. doi: 10.1590/S1984-70332011000500005

Jiang, C.-H., Huang, Z.-Y., Xie, P., Gu, C., Li, K., Wang, D.-C., et al. (2016). Transcription factors WRKY70 and WRKY11 served as regulators in rhizobacterium Bacillus cereus AR156-induced systemic resistance to Pseudomonas syringae pv.tomato DC3000 in Arabidopsis. J. Exp. Bot. 67, 157-174. doi: 10.1093/jxb/erv445

Langmead, B., and Salzberg, S. L. (2012). Fast gapped-read alignment with Bowtie 2. Nat. Methods 9, 357-359. doi: 10.1038/nmeth.1923

Lapointe, S. L., Serrano, M. S., Arango, G. L., Sotelo, G., and Cordoba, F. (1992). Antibiosis to spittlebugs (Homoptera: Cercopidae) in accessions of Brachiaria spp. J. Econ. Entomol. 85, 1485-1490. doi: 10.1093/jee/85.4.1485

Lechner, E., Achard, P., Vansiri, A., Potuschak, T., and Genschik, P. (2006). F-box proteins everywhere. Curr. Opin. Plant Biol. 9, 631-638. doi: 10.1016/j.pbi.2006. 09.003

Li, P., and Brutnell, T. P. (2011). Setaria viridis and Setaria italica, model genetic systems for the Panicoid grasses. J. Exp. Bot. 62, 3031-3037. doi: 10.1093/jxb/ err096 
Liu, J.-J., Sturrock, R., and Ekramoddoullah, A. K. M. (2010). The superfamily of thaumatin-like proteins: its origin, evolution, and expression towards biological function. Plant Cell Rep. 29, 419-436. doi: 10.1007/s00299-010-0826-8

Lu, F., Lipka, A. E., Glaubitz, J., Elshire, R., Cherney, J. H., Casler, M. D., et al. (2013). Switchgrass genomic diversity, ploidy, and evolution: novel insights from a network-based SNP discovery protocol. PLoS Genet. 9:e1003215. doi: 10.1371/journal.pgen.1003215

Ma, J.-Q., Yao, M.-Z., Ma, C.-L., Wang, X.-C., Jin, J.-Q., Wang, X.-M., et al. (2014). Construction of a SSR-based genetic map and identification of QTLs for catechins content in tea plant (Camellia sinensis). PLoS One 9:e93131. doi: 10.1371/journal.pone.0093131

Manrique-Carpintero, N. C., Coombs, J. J., Veilleux, R. E., Buell, C. R., and Douches, D. S. (2016). Comparative analysis of regions with distorted segregation in three diploid population of potato. G3 6, 2617-2628. doi: 10 . 1534/g3.116.030031

Margarido, G. R. A., and Heckerman, D. (2015). ConPADE: genome assembly ploidy estimation from next-generation sequencing data. PLoS Comput. Biol. 11:e1004229. doi: 10.1371/journal.pcbi.1004229

Margarido, G. R. A., Souza, A. P., and Garcia, A. A. F. (2007). OneMap: software for genetic mapping in outcrossing species. Hereditas 144, 78-79. doi: 10.1111/ j.2007.0018-0661.02000.x

Mendes-Bonato, A. B., Pagliarini, M. S., Da Silva, N., and Do Valle, C. B. (2001). Meiotic instability in invader plants of signal grass Brachiaria decumbens Stapf (Gramineae). Acta Sci. 23, 619-625.

Metzler, M. C., Cutt, J. R., and Klessig, D. F. (1991). Isolation and characterization of a gene encoding a PR-1-like protein from Arabidopsis thaliana. Plant Physiol. 96, 346-348. doi: 10.1104/pp.96.1.346

Miles, J. W., Cardona, C., and Sotelo, G. (2006). Recurrent selection in a synthetic brachiariagrass population improves resistance to three spittlebug species. Crop Sci. 46, 1088-1093. doi: 10.2135/cropsci2005.06-0101

Miles, J. W., Lapointe, S. L., Escandén, M. L., and Sotelo, G. (1995). Inheritance of resistance to spittle bug (Homoptera: Cercopidae) in inter specific Brachiaria spp. hybrids. J. Econ. Entomol. 88, 1477-1481. doi: 10.1093/jee/88.5.1477

Misra, R. C., Sandeep, Kamthan, M., Kumar, S., and Ghosh, S. (2016). A thaumatinlike protein of Ocimum basilicum confers tolerance to fungal pathogen and abiotic stress in transgenic Arabidopsis. Sci. Rep. 6:25340. doi: 10.1038/ srep 25340

Mollinari, M., and Serang, O. (2015). Quantitative SNP genotyping of polyploids with MassARRAY and other platforms. Methods Mol. Biol. 1245, 215-241. doi: 10.1007/978-1-4939-1966-6_17

Mukherjee, A. K., Carp, M.-J., Zuchman, R., Ziv, T., Horwitz, B. A., and Gepstein, S. (2010). Proteomics of the response of Arabidopsis thaliana to infection with Alternaria brassicicola. J. Proteom. 73, 709-720. doi: 10.1016/j.jprot.2009. 10.005

Naumova, T. N., Hayward, M. D., and Wagenvoort, M. (1999). Apomixis and sexuality in diploid and tetraploid accessions of Brachiaria decumbens. Sex Plant Reprod. 12, 43-52. doi: 10.1007/s004970050170

Okada, M., Lanzatella, C., Saha, M. C., Bouton, J., Wu, R., and Tobias, C. M. (2010). Complete switchgrass genetic maps reveal subgenome collinearity, preferential pairing and multilocus interactions. Genetics 185, 745-760. doi: 10.1534/genetics.110.113910

Oki, N., Kaga, A., Shimizu, T., Takahashi, M., Kono, Y., and Takahashi, M. (2017). QTL mapping of antixenosis resistance to common cutworm (Spodoptera litura Fabricius) in wild soybean (Glycine soja). PLoS One 12:e0189440. doi: 10.1371/ journal.pone. 0189440

Patel, R. K., and Jain, M. (2012). NGS QC toolkit: a toolkit for quality control of next generation sequencing data. PLoS One 7:e30619. doi: 10.1371/journal. pone.0030619

Pereira, G. S., Garcia, A. A. F., and Margarido, G. R. A. (2018). A fully automated pipeline for quantitative genotype calling from next generation sequencing data in polyploids. BMC Bioinform. 19:398. doi: 10.1186/s12859-018-2433-6

Pessoa-Filho, M., Martins, A. M., and Ferreira, M. E. (2017). Molecular dating of phylogenetic divergence between Urochloa species based on complete chloroplast genomes. BMC Genom. 18:516. doi: 10.1186/s12864-017-3904-2

Piepho, H. P., and Möhring, J. (2007). Computing heritability and selection response from unbalanced plant breeding trials. Genetics 177, 1881-1888. doi: 10.1534/genetics.107.074229

Poland, J. A., Brown, P. J., Sorrells, M. E., and Jannink, J.-L. (2012). Development of high-density genetic maps for barley and wheat using a novel two-enzyme genotyping-by-sequencing approach. PLoS One 7:e32253. doi: 10.1371/journal. pone. 0032253

Poland, J. A., and Rife, T. W. (2012). Genotyping-by-sequencing for plant breeding and genetics. Plant Genome J. 5, 92-102. doi: 10.3835/plantgenome2012.05. 0005

R Core Team (2018). R: A Language and Environment for Statistical Computing. Vienna: R Foundation for Statistical Computing.

Renvoize, S. A., Clayton, W. D., and Kabuye, C. H. S. (1996). "Morphology, taxonomy, and natural distribution of Brachiaria (Trin.). Griseb," in Brachiaria: Biology, Agronomy, and Improvement, eds J. W. Miles, B. L. Maass, and C. B. Valle (Cali: Centro Internacional de Agricultura Tropical (CIAT)), 1-15.

Ripol, M. I., Churchill, G. A., da Silva, J. A. G., and Sorrells, M. (1999). Statistical aspects of genetic mapping in autopolyploids. Gene 235, 31-41. doi: 10.1016/ S0378-1119(99)00218-8

Salgado, L. R., Lima, R., Santos, B. F. D., Shirakawa, K. T., Vilela, M. D. A., Almeida, N. F., et al. (2017). De novo RNA sequencing and analysis of the transcriptome of signalgrass (Urochloa decumbens) roots exposed to aluminum. Plant Growth Regul. 83, 157-170. doi: 10.1007/s10725-017-0291-2

Samayoa, L. F., Malvar, R. A., McMullen, M. D., and Butrón, A. (2015). Identification of QTL for resistance to Mediterranean corn borer in a maize tropical line to improve temperate germplasm. BMC Plant Biol. 15:265. doi: 10.1186/s12870-015-0652-9

Schwarz, G. (1978). Estimating the dimension of a model. Ann. Stat. 6, 461-464. doi: $10.1214 / \mathrm{aos} / 1176344136$

Serang, O., Mollinari, M., and Garcia, A. A. F. (2012). Efficient exact maximum a posteriori computation for Bayesian SNP genotyping in polyploids. PLoS One 7:e30906. doi: 10.1371/journal.pone.0030906

Shirasawa, K., Tanaka, M., Takahata, Y., Ma, D., Cao, Q., Liu, Q., et al. (2017). A high-density SNP genetic map consisting of a complete set of homologous groups in autohexaploid sweetpotato (Ipomoea batatas). Sci. Rep. 7:44207. doi: $10.1038 /$ srep 44207

Simioni, C., and Valle, C. B. (2009). Chromosome duplication in Brachiaria (A. Rich.) stapf allows intraspecific crosses. Crop Breed. Appl. Biotechnol. 9, 328-334. doi: 10.12702/1984-7033.v09n04a07

Sinha, M., Singh, R. P., Kushwaha, G. S., Iqbal, N., Singh, A., Kaushik, S., et al. (2014). Current overview of allergens of plant pathogenesis related protein families. Sci. World J. 2014:543195. doi: 10.1155/2014/543195

Song, H., Wang, P., Li, C., Han, S., Zhao, C., Xia, H., et al. (2017). Comparative analysis of NBS-LRR genes and their response to Aspergillus flavus in Arachis. PLoS One 12:e0171181. doi: 10.1371/journal.pone.0171181

Souza, J. S., Chiari, L., Simeão, R. M., de Mendonça Vilela, M., and Salgado, L. R. (2018). Development, validation and characterization of genic microsatellite markers in Urochloa species. Am. J. Plant Sci. 09, 281-295. doi: 10.4236/ajps. 2018.92023

Souza, T. P., Dias, R. O., and Silva-Filho, M. C. (2017). Defense-related proteins involved in sugarcane response to biotic stress. Gent. Mol. Biol. 40, 360-372. doi: 10.1590/1678-4685-GMB-2016-0057

Stebbins, G. L. (1947). Types of polyploids: their classification and significance. Adv. Genet. 1, 403-429. doi: 10.1016/S0065-2660(08)60490-3

Stein, J., Pessino, S. C., Martínez, E. J., Rodriguez, M. P., Siena, L. A., Quarin, C. L., et al. (2007). A genetic map of tetraploid Paspalum notatum Flügge (bahiagrass) based on single-dose molecular markers. Mol. Breed. 20, 153-166. doi: 10.1007/s11032-007-9083-0

Thaikua, S., Ebina, M., Yamanaka, N., Shimoda, K., Suenaga, K., and Kawamoto, Y. (2016). Tightly clustered markers linked to an apospory-related gene region and quantitative trait loci mapping for agronomic traits in Brachiaria hybrids. Grassl. Sci. 62, 69-80. doi: 10.1111/grs.12115

Triviño, N. J., Perez, J. G., Recio, M. E., Ebina, M., Yamanaka, N., Tsuruta, S.-I., et al. (2017). Genetic diversity and population structure of species and breeding populations. Crop Sci. 57, 1-12. doi: 10.2135/cropsci2017.01. 0045

Valério, J., and Nakano, O. (1988). Influência do adulto de Zulia entreriana (Berg, 1879) (Homoptera: Cercopidae) na produção e qualidade de Brachiaria decumbens. Pesqui. Agropecu. Bras. 23, 447-453.

Valério, J., and Nakano, O. (1992). Sintomatologia dos danos causados pelo adulto da cigarrinha Zulia entreriana (Berg, 1879) (Homoptera: Cercopidae) em Brachiaria decumbens Stapf. Ann. Soc. Entomol. Bras. 21, 95-100.

Valério, J. R., Jeller, H., and Peixer, J. (1997). Seleção de introduções do gênero Brachiaria (Griseb) resistentes à cigarrinha Zulia entreriana (Berg) 
(Homoptera: Cercopidae). Ann. Soc. Entomol. Bras. 26, 383-387. doi: 10.1590/ S0301-80591997000200023

Valle, C. B., Jank, L., and Resende, R. M. S. (2009). O melhoramento de forrageiras tropicais no Brasil. Rev. Ceres 56, 460-472.

Valle, C. B., Macedo, M. C. M., Euclides, V. P. B., Jank, L., and Resende, R. (2010). "Gênero brachiaria," in Plantas Forrageiras, eds D. M. D. F. Martuscello and J. Azevedo (Viçosa: Editora UFV), 30-77.

Valle, C. B., Simioni, C., Resende, R. M. S., and Jank, L. (2008). "Melhoramento genético de Brachiaria," in Melhoramento de Forrageiras Tropicais, eds R. M. S. Resende, C. B. Valle, and L. Jank (Campo Grande, MS: Embrapa Gado de Corte), 13-54.

Van loon, L. C., Rep, M., and Pieterse, C. M. J. (2006). Significance of inducible defense-related proteins in infected plants. Annu. Rev. Phytopathol. 44, 135162. doi: 10.1146/annurev.phyto.44.070505.143425

Van Loon, L. C., and Van Strien, E. A. (1999). The families of pathogenesisrelated proteins, their activities, and comparative analysis of PR-1 type proteins. Physiol. Mol. Plant Pathol. 55, 85-97. doi: 10.1006/pmpp.1999. 0213

Van ooijen, G., Mayr, G., Kasiem, M. M. A., Albrecht, M., Cornelissen, B. J. C., and Takken, F. L. W. (2008). Structure-function analysis of the nb-arc domain of plant disease resistance proteins. J. Exp. Bot. 59, 1383-1397. doi: 10.1093/jxb/ ern045

Vigna, B. B. Z., Santos, J. C. S., Jungmann, L., do Valle, C. B., Mollinari, M., Pastina, M. M., et al. (2016). Evidence of allopolyploidy in Urochloa humidicola based on cytological analysis and genetic linkage mapping. PLoS One 11:e0153764. doi: 10.1371/journal.pone.0153764

Voorrips, R. E. (2002). MapChart: software for the graphical presentation of linkage maps and QTLs. J. Hered. 93, 77-78. doi: 10.1093/jhered/93.1.77

Voorrips, R. E., Gort, G., and Vosman, B. (2011). Genotype calling in tetraploid species from bi-allelic marker data using mixture models. BMC Bioinform. 12:172. doi: 10.1186/1471-2105-12-172
Vosman, B., Kashaninia, A., van't Westenede, W., Meijer-Dekens, F., van Eekelen, H., Visser, R. G. F., et al. (2018). QTL mapping of insect resistance components of Solanum galapagense. Theor. Appl. Genet. 132, 531-541. doi: 10.1007/s00122-018-3239-7

War, A. R., Paulraj, M. G., Ahmad, T., Buhroo, A. A., Hussain, B., Ignacimuthu, S., et al. (2012). Mechanisms of plant defense against insect herbivores. Plant Signal. Behav. 7, 1306-1320. doi: 10.4161/psb.21663

Worthington, M., Heffelfinger, C., Bernal, D., Quintero, C., Zapata, Y. P., Perez, J. G., et al. (2016). A parthenogenesis gene candidate and evidence for segmental allopolyploidy in apomictic Brachiaria decumbens. Genetics 203, 1117-1132. doi: 10.1534/genetics.116.190314

Wu, K. K., Burnquist, W., Sorrells, M. E., Tew, T. L., Moore, P. H., and Tanksley, S. D. (1992). The detection and estimation of linkage in polyploids using single-dose restriction fragments. Theor. Appl. Genet. 83, 294-300. doi: 10.1007/ BF00224274

Xing, H., Fu, X., Yang, C., Tang, X., Guo, L., Li, C., et al. (2018). Genomewide investigation of pentatricopeptide repeat gene family in poplar and their expression analysis in response to biotic and abiotic stresses. Sci. Rep. 8:2817. doi: 10.1038/s41598-018-21269-1

Conflict of Interest Statement: The authors declare that the research was conducted in the absence of any commercial or financial relationships that could be construed as a potential conflict of interest.

Copyright (c) 2019 Ferreira, Lara, Chiari, Barrios, do Valle, Valério, Torres, Garcia and de Souza. This is an open-access article distributed under the terms of the Creative Commons Attribution License (CC BY). The use, distribution or reproduction in other forums is permitted, provided the original author $(s)$ and the copyright owner(s) are credited and that the original publication in this journal is cited, in accordance with accepted academic practice. No use, distribution or reproduction is permitted which does not comply with these terms. 